\title{
SB225002 inhibits prostate cancer invasion and attenuates the expression of BSP, OPN and MMP-2
}

\author{
MENG XU ${ }^{1}$, HUAMAO JIANG ${ }^{2}$, HAIGUANG WANG ${ }^{1}$, JIAJIE LIU ${ }^{1}$, BAOHAO LIU ${ }^{1}$ and ZHONGQIANG GUO ${ }^{1}$ \\ ${ }^{1}$ Department of Urology, The First Affiliated Hospital of Jinzhou Medical University; \\ ${ }^{2}$ Graduate School of Jinzhou Medical University, Jinzhou, Liaoning 121000, P.R. China
}

Received October 18, 2017; Accepted May 31, 2018

DOI: 10.3892/or.2018.6504

\begin{abstract}
The mechanisms of malignant cell metastasis to secondary sites are complex and multifactorial. Studies have demonstrated that small integrin-binding ligand $\mathrm{N}$-linked glycoproteins (SIBLINGs), particularly bone sialoprotein (BSP) and osteopontin (OPN), are involved in neoplastic growth and metastasis. SIBLINGs promote malignant cell invasion and metastasis by enhancing matrix metalloproteinase 2 (MMP-2) and MMP-9 expression. Moreover, BSP and OPN can combine with integrin, which is located on the tumor cell surface, to further promote the malignant behavior of tumor cells. In the present study, we investigated whether SB225002, a specific CXCR2 receptor antagonist, can inhibit prostate cancer cell expression of BSP and OPN and reduce cancer cell invasion ability. A series of experiments showed that after SB225002 treatment, the proliferation, invasion and migration of two androgen-independent prostate cancer cell lines were inhibited, but this inhibitory effect was not observed on androgen-dependent prostate cancer cells. Western blotting showed that the PI3K signaling pathway could regulate the expression of SIBLING and MMP family proteins, and SB22055 could reduce the expression of BSP, OPN and MMP-2 in prostate cancer cells by inhibiting AKT/mTOR phosphorylation. Finally, in vivo experiments confirmed that SB225002 inhibited the proliferation of prostate cancer cells in vivo, and the expression levels of BSP, OPN and MMP-2 were also inhibited.
\end{abstract}

\section{Introduction}

Metastasis is a major obstacle in cancer therapy; despite constant standardization of chemotherapy or surgical procedures $(1,2)$, some patients die due to distant metastasis of tumor cells. The purpose of this experiment was to explore a new method to inhibit the invasion of tumor cells more efficiently.

Correspondence to: Dr Huamao Jiang, Graduate School of Jinzhou Medical University, Songpo Road, Jinzhou, Liaoning 121000, P.R. China E-mail: lyyyjhm@163.com

Key words: prostate cancer, invasion, SB225002, bone sialoprotein, osteopontin
Tumor metastasis is a multistage process during which malignant cells spread from the primary tumor to distant organs (3). With the participation of multiple proteins and cytokines, tumor cells infiltrate the circulatory system and avoid immune system attacks, eventually reaching target organs for implantation and growth (4). The SIBLING (small integrin-binding ligand N-linked glycoprotein) family of proteins regulates malignant tumor behaviors such as malignant cell proliferation, detachment, invasion, and metastasis by combining with integrin protein (5). SIBLINGs are overexpressed in many cancers $(2,6-8)$. The level of SIBLING protein in serum is often used to predict the prognosis of many cancer patients, especially in patients with prostate and breast cancer (9-11). Two proteins in this family, namely, OPN (osteopontin) and BSP (bone sialoprotein), have garnered the most attention, and their reported levels of expression are closely correlated with tumor aggressiveness. For invasion, BSP and OPN can activate specific metalloproteinases (BSP activates MMP-2, OPN activates MMP-3) to enhance the ability of cancer cells to hydrolyze the extracellular matrix (ECM) $(6,12)$. The binding of BSP and integrins contributes to metastasis formation of breast cancer cells, particularly bone metastasis (13). Moreover, BSP-transfected breast cancer cells showed increased primary tumor growth following injection into the mammary fat pad of nude mice (14), and OPN stimulated human prostate cancer $(\mathrm{PCa})$ cell proliferation when transferred to a mouse xenograft model system (15). These effects mainly occurred through BSP and OPN activation of the epidermal growth factor receptor (EGFR) and integrin-mediated intracellular $\mathrm{Ca}^{2+}$ signaling (16). Therefore, it is important to identify a method that can inhibit the expression of BSP and OPN in tumor cells to prevent tumor cell metastasis.

Studies have suggested that interleukin-8 (IL-8) and its cognate receptors, namely, $\mathrm{C}-\mathrm{X}-\mathrm{C}$ chemokine receptor-1 (CXCR1) and CX-C chemokine receptor-2 (CXCR2), mediate the initiation and development of various types of cancers, including breast cancer, PCa, lung cancer, colorectal carcinoma and melanoma (17-21). IL-8 also integrates with multiple intracellular signaling pathways to produce coordinated effects. In terms of invasion, IL-8 promotes prostate and breast cancer expression of matrix metalloproteinases (MMPs) (especially MMP-2 and MMP-9) to enhance their cell aggressiveness $(22,23)$. The ectopic expression of IL-8 
stimulated by IL- $1 \beta$ and TNF- $\alpha$ can enhance the metastatic potential of breast cancer since a high level of IL-8 can promote angiogenesis and attract neutrophils to release enzymes involved in tissue remodeling and tumor establishment (24). Increased IL- 8 secretion by PCa cells is similarly associated with the malignant biological behaviors of cancer cells. IL-8/CXCR2 promotes castration-resistant growth and proliferation of AIPC cells (androgen-independent PCa cells) by activating cyclin D1 expression in a PI3K/Akt/mTOR and MAPK pathway-dependent manner $(25,26)$.

SB22502 is a specific CXCR2 receptor antagonist, and studies have shown that SB225002 induces apoptosis in ovarian cancer cells and cell death and cell cycle arrest in acute lymphoblastic leukemia cells $(27,28)$. However, few studies have described the inhibition of cancer cell invasion or metastasis by SB225002. This study shows for the first time that SB225002-treated human PCa DU-145, LNCAP and PC-3 cells exhibited reduced invasion ability. At the same time, we detected the expression of BSP, OPN, MMP-2, MMP-9 and $\alpha v \beta 3$ after treatment with SB225002 and different signaling pathway inhibitors to further clarify the underlying molecular mechanism of SB225002 function in PCa cells.

\section{Materials and methods}

Cells and culture. Human androgen-independent prostate cancer DU-145 cells were obtained from Biotechnology Company (Shenyang, China) and were cultured in MEM medium (Corning Inc., Corning, NY, USA), supplemented with $10 \% \mathrm{FBS}$ and $1 \%$ penicillin/streptomycin and cultured in $5 \% \mathrm{CO}_{2}$ at $37^{\circ} \mathrm{C}$. Androgen-independent prostate cancer PC-3 cells and androgen-dependent prostate cancer LNCAP cells were provided by the Brain and Spinal Injury Laboratory of Liaoning Province (Liaoning, China). PC-3 cells were cultured in F-12, and LNCAP cells were cultured in RPMI-1640; the other culture conditions were the same as those of DU-145 cells.

Reagents and treatment. LY294002 (Akt inhibitor), U0126 (ERK1/2 inhibitor), SB203580 (p38 MAPK inhibitor), SP600125 (JNK1/2 inhibitor) and SB225002 (CXCR2 receptor antagonist) were purchased from Selleck Chemicals (Houston, TX, USA). The primary antibodies for PI3K (cat. no. sc-71891), AKT (cat. no. sc-5270)/p-AKT (cat. no. sc-271966) and mTOR (cat. no. sc-293089PE)/ p-mTOR (cat. no. sc-293133) were purchased from Santa Cruz Biotechnology (Santa Cruz, CA, USA). Antibodies for MMP-2 (WL1579), MMP-9 (WL01580), and OPN (WL02848) were obtained from Wanleibio (Shenyang, China). BSP (BA2329) was purchased from Boster Biological Technology (Wuhan, China). $\alpha v \beta 3$ (bs-1310R) and p-PI3K (bs-6417R) were purchased from Bioss Biological Technology (Beijing, China). MTT and DAPI were provided by Solarbio (Beijing, China), and Transwell Matrigel was purchased from Corning Inc. The anti-human BSP Elisa kit was purchased from AMEKO (Shanghai Lianshuo Biological Technology Co., Ltd., Shanghai, China).

Cell viability analysis. Three PCa cell lines were seeded into 96-well plates (at a cell density of $2 \times 10^{3}$ cells/well) cultured in normal growth medium and treated with different concentrations of SB225002 $(0,1,3,5,10$ and $15 \mu \mathrm{M})$ for $72 \mathrm{~h}$. After incubation, MTT solution $(0.5 \mathrm{mg} / \mathrm{ml})$ was added to each well, and the plates were incubated in a humidified incubator at $37^{\circ} \mathrm{C}$ for $4 \mathrm{~h}$. At the end of the incubation period, the medium was removed, formazan was dissolved in DMSO, and the optical densities were determined at $490 \mathrm{~nm}$ using a microplate reader. The cell growth inhibition rate was calculated using the following equation: Cell growth inhibition rate $=1$-(absorbance of experimental value/absorbance of control).

Migration and invasion assays. In vitro invasion was determined in 24-well Transwell inserts with $8-\mu \mathrm{m}$ pore-size filters. The basement membrane Matrigel was diluted to $200 \mu \mathrm{g} / \mathrm{ml}$ with serum-free RPMI-1640 medium, and the filters were coated with $100 \mu \mathrm{l}$ of basement membrane Matrigel, air-dried and hydrated with $100 \mu \mathrm{l}$ of serum-free RPMI-1640 per well for $30 \mathrm{~min}$ prior to cell addition. Cells were added to the upper chamber inserts at a concentration of $5 \times 10^{4}$ cells in $0.2 \mathrm{ml}$ of serum-free medium (at least 3 replicates for each sample). Three media $(500 \mathrm{ml})$ containing $20 \%$ FBS were added to the lower chamber. In the SB225002 group, $5 \mu \mathrm{M}$ of the drug was added. After incubation for $48 \mathrm{~h}$ at $37^{\circ} \mathrm{C}$, cells in the upper part of the Transwells were removed with a cotton swab, and the chambers were washed with PBS. Cells that had migrated were fixed with $4 \%$ paraformaldehyde and stained with $0.1 \%$ crystal violet for $10 \mathrm{~min}$ (13). At the same time, the experimental group and the control group without Matrigel were set up to calculate the invasion rate of the cancer cells. For migration, cells were plated in 6-well plates at a density of $5 \times 10^{5}$ cells per well until they reached $90 \%$ confluence. A single wound was scraped with a pipette tip (200 $\mu \mathrm{l}$ was used) in the center of the cell monolayer, and the wells were washed with PBS to remove cell debris. After an additional $48 \mathrm{~h}$ of culture, wound healing was visualized with an inverted microscope (Olympus IX51; Olympus Corp., Tokyo, Japan).

Western blot analysis. Cells were harvested and lysed with lysis buffer containing the protease inhibitor phenylmethylsulfonyl fluoride (PMSF). Each group of protein samples was quantified using the BSA Protein Quantification kit. Equal amounts of protein ( $20 \mu \mathrm{g} / \mathrm{lane})$ from the sample were electrophoresed on $10 \%$ SDS-PAGE gels and were transferred to PVDF membranes. The membranes were blocked with $5 \%$ skim milk in TBS containing $0.1 \%$ Tween-20 for $1 \mathrm{~h}$ at room temperature. After washing with TBST three times, the membranes were co-incubated with the primary antibody (1:500 for anti-BSP, 1:500 for anti-MMP2, 1:500 for GAPDH) overnight at $4^{\circ} \mathrm{C}$ in TBST. After incubation with horseradish peroxidase (HRP) goat anti-rabbit IgG $(1: 10,000)$ in TBST for $60 \mathrm{~min}$, the proteins were visualized using the ECL detection kit (Wanleibio). Imaging system used ImageQuant ${ }^{\mathrm{TM}}$ LAS 4000 (GE Healthcare, Chicago, IL, USA).

Tumor xenografts. Fifteen BALB/c mice (as SIBLING proteins help tumor cells escape immune system attack, nude mice were not selected) weighing 18-22 g were obtained from the Brain and Spinal Injury Laboratory of Liaoning (Liaoning, China) and reared at a temperature $18-29^{\circ} \mathrm{C}$; relative humidity 50-60\%; ventilation 8-12 times/h; light 10-12 $\mathrm{h} / \mathrm{day}$, and were randomly divided into three groups: untreated 
Table I. MTT assay was used to detect the inhibitory effect of SB225002 on prostate cancer cell proliferation.

A, DU-145

\begin{tabular}{|c|c|c|c|c|c|c|}
\hline \multirow{2}{*}{$\begin{array}{l}\mathrm{SB} 225002 \\
(\mu \mathrm{mol} / \mathrm{l})\end{array}$} & \multicolumn{3}{|c|}{$\mathrm{OD}(\mathrm{n}=3, \overline{\mathrm{x}} \pm \mathrm{SD})$} & \multicolumn{3}{|c|}{ Inhibition rate of cell growth (\%) } \\
\hline & $24 \mathrm{~h}$ & $48 \mathrm{~h}$ & $72 \mathrm{~h}$ & $24 \mathrm{~h}$ & $48 \mathrm{~h}$ & $2 \mathrm{~h}$ \\
\hline 0 & $0.211 \pm 0.023$ & $0.274 \pm 0.197$ & $0.281 \pm 0.026$ & 0.00 & 0.00 & 0.00 \\
\hline 5 & $0.109 \pm 0.017$ & $0.137 \pm 0.013$ & $0.110 \pm 0.028$ & 48.34 & 50.00 & 60.85 \\
\hline 10 & $0.059 \pm 0.015$ & $0.042 \pm 0.010$ & $0.003 \pm 0.001$ & 72.22 & 84.85 & 98.91 \\
\hline 15 & $0.026 \pm 0.012$ & $0.021 \pm 0.009$ & $0.002 \pm 0.001$ & 87.81 & 92.34 & 99.01 \\
\hline
\end{tabular}

$\mathrm{B}, \mathrm{PC}-3$

\begin{tabular}{|c|c|c|c|c|c|c|}
\hline \multirow{2}{*}{$\begin{array}{l}\mathrm{SB} 225002 \\
(\mu \mathrm{mol} / \mathrm{l})\end{array}$} & \multicolumn{3}{|c|}{$\mathrm{OD}(\mathrm{n}=3, \overline{\mathrm{x}} \pm \mathrm{SD})$} & \multicolumn{3}{|c|}{ Inhibition rate of cell growth (\%) } \\
\hline & $24 \mathrm{~h}$ & $48 \mathrm{~h}$ & $72 \mathrm{~h}$ & $24 \mathrm{~h}$ & $48 \mathrm{~h}$ & $2 \mathrm{~h}$ \\
\hline 0 & $0.203 \pm 0.019$ & $0.272 \pm 0.109$ & $0.293 \pm 0.016$ & 0.00 & 0.00 & 0.00 \\
\hline 5 & $0.119 \pm 0.007$ & $0.138 \pm 0.013$ & $0.108 \pm 0.034$ & 41.37 & 49.29 & 63.13 \\
\hline 10 & $0.077 \pm 0.026$ & $0.041 \pm 0.031$ & $0.003 \pm 0.001$ & 62.11 & 84.79 & 99.01 \\
\hline 15 & $0.038 \pm 0.022$ & $0.019 \pm 0.009$ & $0.004 \pm 0.001$ & 81.27 & 93.12 & 98.70 \\
\hline
\end{tabular}

\section{C, LNCAP}

\begin{tabular}{|c|c|c|c|c|c|c|}
\hline \multirow{2}{*}{$\begin{array}{l}\mathrm{SB} 225002 \\
(\mu \mathrm{mol} / \mathrm{l})\end{array}$} & \multicolumn{3}{|c|}{$\mathrm{OD}(\mathrm{n}=3, \overline{\mathrm{x}} \pm \mathrm{SD})$} & \multicolumn{3}{|c|}{ Inhibition rate of cell growth $(\%)$} \\
\hline & $24 \mathrm{~h}$ & $48 \mathrm{~h}$ & $72 \mathrm{~h}$ & $24 \mathrm{~h}$ & $48 \mathrm{~h}$ & $2 \mathrm{~h}$ \\
\hline 0 & $0.224 \pm 0.011$ & $0.247 \pm 0.034$ & $0.291 \pm 0.020$ & 0.00 & 0.00 & 0.00 \\
\hline 5 & $0.140 \pm 0.003$ & $0.136 \pm 0.060$ & $0.152 \pm 0.024$ & 37.70 & 45.02 & 47.77 \\
\hline 10 & $0.120 \pm 0.036$ & $0.125 \pm 0.031$ & $0.123 \pm 0.071$ & 47.27 & 49.44 & 57.89 \\
\hline 15 & $0.108 \pm 0.023$ & $0.092 \pm 0.019$ & $0.042 \pm 0.017$ & 51.71 & 62.70 & 85.27 \\
\hline
\end{tabular}

The MTT assay was used to detected SB225002 inhibition of cell proliferation in three PCa cell lines. For DU-145 and PC-3 cells, the inhibition rate with $5 \mu \mathrm{M} \mathrm{SB} 225002$ at $48 \mathrm{~h}$ reached 50\%; however, the inhibitory effect of SB225002 on LNCAP cells was not obvious, $85 \%$ at $72 \mathrm{~h}$ with $15 \mu \mathrm{M} \mathrm{SB} 225002$. The values represent means $\pm \mathrm{SD}$, and MTT assay data are representative of at least 3 independent experiments.

group, DU-145 implantation group and DU-145 implantation + SB225002 injection group. The number of cells implanted was $1 \times 10^{6} /$ mouse. All the procedures were performed in accordance with the Regulations of Experimental Animal Administration issued by the Ministry of Science and Technology of China. The tumor volume (V) was measured at 1 week $(\mathrm{W})$ and $2 \mathrm{~W}$ after DU-145 implantation and SB225002 injection, and the measurements were calculated as $\mathrm{V}=\left(\right.$ length $\mathrm{x}$ width $\left.{ }^{2}\right) / 2$.

Immunohistochemistry. After xenograft implantation was completed at $1 \mathrm{~W}$ and $2 \mathrm{~W}$, the tumors were harvested, paraffin embedded, deparaffinized and rehydrated through a gradient alcohol series using standard protocols. Next, endogenous peroxidase was inactivated with $3 \%$ hydrogen peroxide for 6 min, antigen unmasking was performed by heat retrieval performed using citrate buffer ( $\mathrm{pH}$ 6.1), and the slides were washed in PBS three times. Each group was incubated with the respective primary antibody overnight at $4^{\circ} \mathrm{C}$ in a humid chamber after blocking in goat serum at room temperature for $15 \mathrm{~min}$. Thereafter, anti-rabbit biotinylated secondary antibody was added, followed by incubation at $37^{\circ} \mathrm{C}$ for $1 \mathrm{~h}$, the addition of HRP labeled streptavidin, and incubation at room temperature for $30 \mathrm{~min}$ with DAB color $3 \mathrm{~min}$. Finally, hematoxylin was used to dye the nuclei. The results were evaluated by two pathologists who performed a double-blind reading as follows: Colorless, 0 points; light yellow, 1 point; dark yellow, 2 points; brown, 3 points. The percentage of positive cells was counted in each field. The percentage of positive cells per 100 cells was counted under a upright microscope (Olympus BX53; Olympus Corp.) (magnification, $\mathrm{x} 200$ ): 0 indicates negative, 1 indicates the percentage of positive cells $<10 \%, 2$ indicates the percentage of positive cells $10-50 \%, 3$ indicates the percentage of positive cells $>50-75 \%$, and 4 indicates the percentage of positive cells $>75 \%$. The average score for each group was calculated as the average color depth multiplied by the percentage of the positive cell score. For the final score, $<1$ indicates negative (-), 1-2 

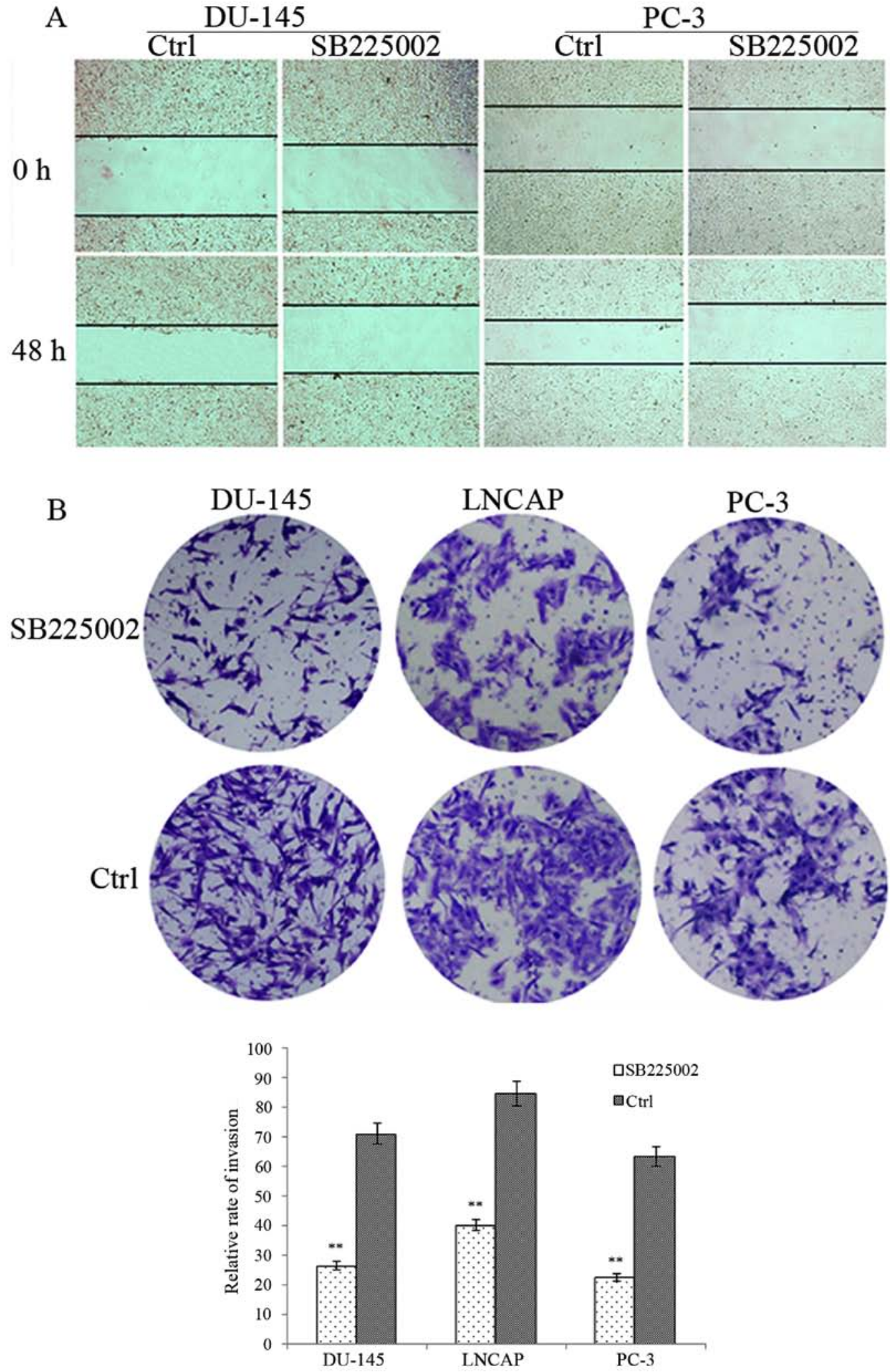

Figure 1. Transwell and migration assays were performed before and after SB225002 treatment. (A) The migration assay showed that although two prostate cancer cell lines showed a slower speed of healing, the wound healing in the SB225002 group was still slower than that of the control group. (B) The Transwell assay indicated that SB225002 suppressed the invasion ability of the three PCa cell lines through the Matrigel barrier. For DU-145 cells, the relative rate of invasion was $26.54 \%$ in the SB225002 group compared with $71.21 \%$ in the control $(\mathrm{P}=0.005)$. For LNCAP cells, the relative rate of invasion was $40.31 \%$ in the SB225002 group compared with $84.64 \%$ in the control $(\mathrm{P}=0.005)$. Finally, for $\mathrm{PC}-3$ cells, the relative rate of invasion was $22.65 \%$ in the SB225002 group and $63.44 \%$ in the control. ${ }^{* *} \mathrm{P}<0.01$. Results of the Transwell assays represent at least 3 independent experiments. PCa, prostate cancer; SB22502, a specific CXCR2 receptor antagonist.

indicates weakly positive (+), $3-4$ indicates positive (++), and $>4$ indicates strongly positive (+++).
ELISA. Enzyme-linked immunosorbent assay was performed to determine whether SB225002 reduced BSP and OPN 
A

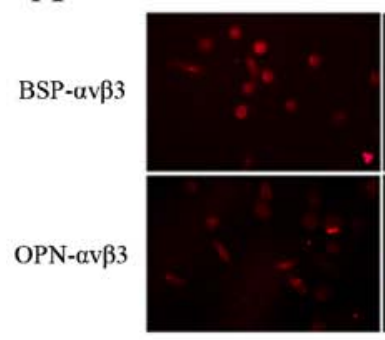

DU-145
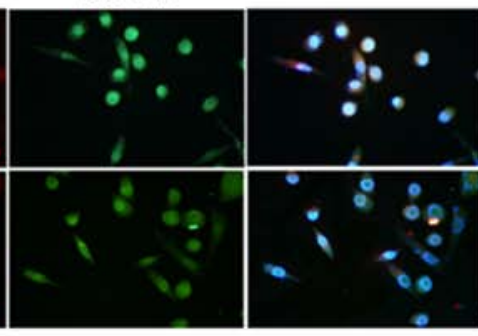

$\mathrm{C}$
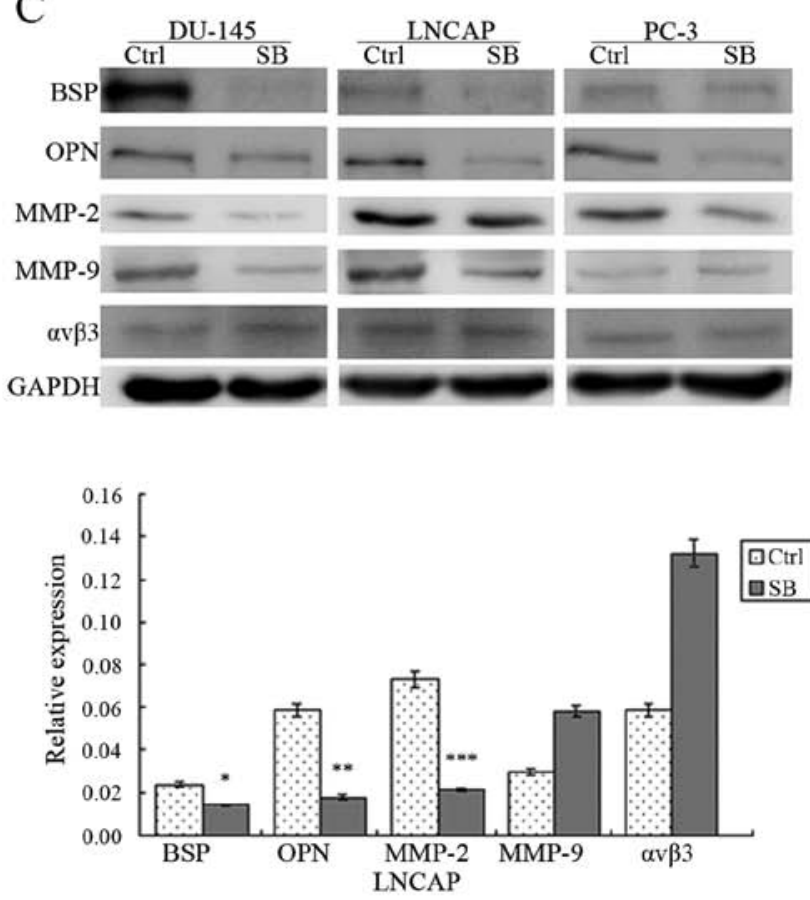

B
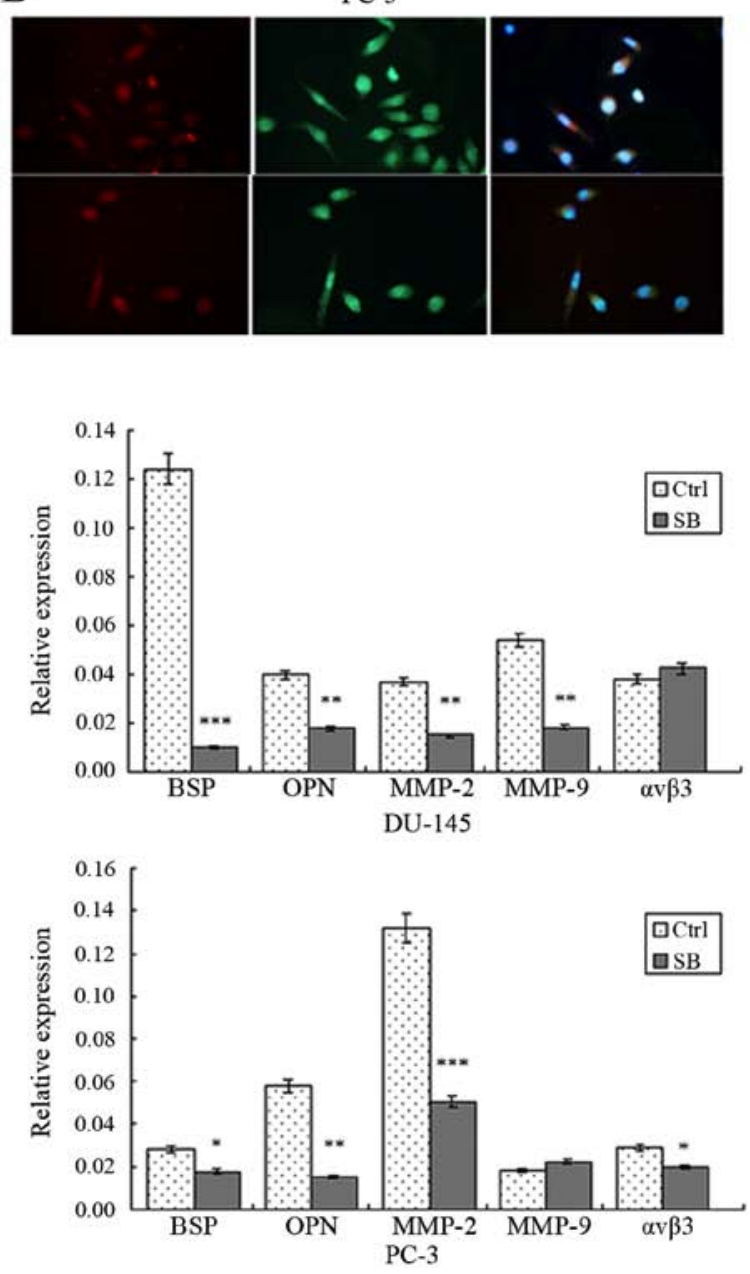

Figure 2. (A and B) Immunofluorescence detected that BSP/OPN and $\alpha v \beta 3$ were co-expressed in DU-145 and PC-3 cells. (C) Western blotting showed that SB225002 reduced expression of BSP, OPN and MMP-2 in the PCa cells $(\mathrm{P}<0.05)$, but not that of MMP-9 and $\alpha \mathrm{v} \beta 3$. Each histogram was compared with the semi-quantitative result of western blot analysis; each experiment was repeated at least 3 times, ${ }^{*} \mathrm{P}<0.05,{ }^{* *} \mathrm{P}<0.01,{ }^{* * *} \mathrm{P}<0.001$. $\mathrm{PCa}$, prostate cancer; $\mathrm{BSP}$, bone sialoprotein; OPN, osteopontin; MMP, metalloproteinase; $\alpha v \beta 3$, integrin alpha $v$ and integrin beta 3; SB, SB22502 (a specific CXCR2 receptor antagonist); Ctrl, control; LY, LY294002 (Akt inhibitor); U0, U0126 (ERK1/2 inhibitor); S, SB203580 (p38 MAPK inhibitor); SP, SP600125 (JNK1/2 inhibitor).

secretion in vivo. At the end of 7 days of SB225002 injection, mouse blood was obtained through eye arteries. After centrifugation at 1,000 rpm for $10 \mathrm{~min}$, the serum was separated from whole-blood samples, and BSP and OPN were detected using the Human BSP/OPN ELISA kit.

Immunofluorescence. DU-145 and PC-3 cells were seeded into 96 -well plates. When the cell density reached $60 \%$, the medium was removed, and the cells were fixed with $4 \%$ paraformaldehyde at room temperature for $30 \mathrm{~min}$. The cells were then permeabilized using Triton X-100, and each well was treated with blocking buffer (1X TBST, 3\% goat serum) for $1 \mathrm{~h}$ at room temperature, followed by overnight incubation at $4^{\circ} \mathrm{C}$ with primary antibodies (BSP, $1: 300 ;$ OPN, $1: 300 ; \alpha v \beta 3$, 1:100) diluted in blocking buffer. The samples were washed 3 times with 1X PBS and were incubated with secondary antibodies for $1 \mathrm{~h}$ before mounting with Prolong Gold antifade reagent (Solarbio, Beijing, China) with DAPI.

Statistical analysis. All the statistical analyses were evaluated using SPSS 21.0 software (IBM Corp., Armonk,
NY, USA). Data are presented as the means \pm SD (standard deviation). Statistical analysis was performed using one-way ANOVA followed by the Bonferroni or Dunnett (2-sided) test for comparisons. The level of significance was set at $\mathrm{P}<0.05$.

\section{Results}

SB225002 inhibits PCa cell proliferation and invasion. The MTT results showed that, after $72 \mathrm{~h}$ of culture, DU-145 and PC-3 proliferation was inhibited in a concentration- and time-dependent manner upon treatment with SB225002. The growth inhibition rate of the DU-145 and PC-3 cells reached $50 \%$ after treatment with $5 \mu \mathrm{M} \mathrm{SB} 225002$ for $48 \mathrm{~h}$, and it reached almost $100 \%$ after treatment with $10 \mu \mathrm{M}$ SB225002 for $72 \mathrm{~h}$. For LNCAP cells, $15 \mu \mathrm{M}$ SB225002 for $72 \mathrm{~h}$ showed an inhibition rate of $85 \%$ (Table I). To further explore the effect of SB225002 on invasion ability, the Transwell assay was used to validate the effect of SB225002 on the invasive ability of PCa cells. After $48 \mathrm{~h}$ of treatment, the number of SB225002-treated cancer cells from the three cell lines 

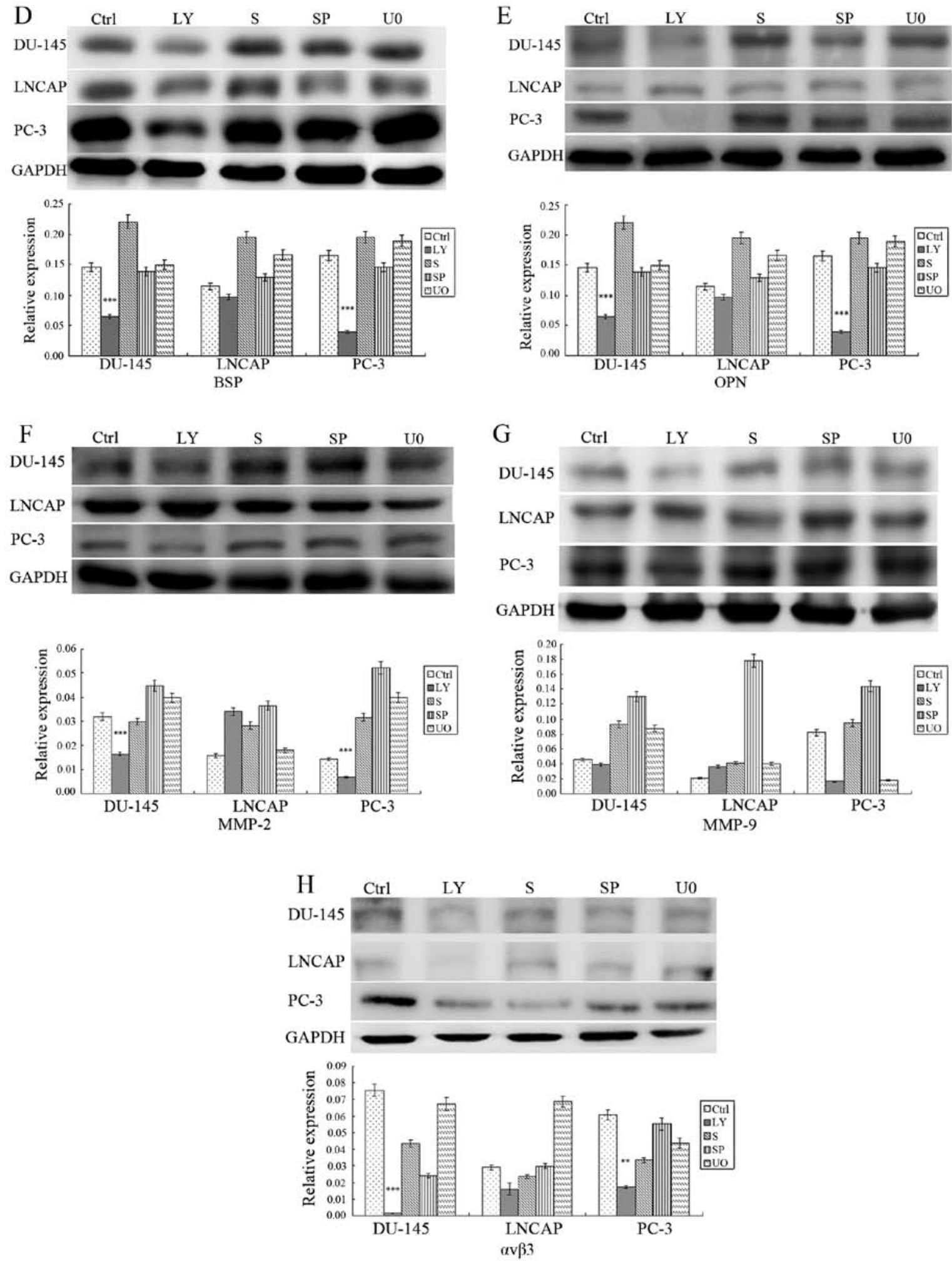

Figure 2. Continued. (D-H) Effect of different signaling pathway inhibitors on BSP, OPN, MMP-2, MMP-9 and $\alpha v \beta 3$ expression. The expression levels of BSP, OPN, MMP-2 and $\alpha \mathrm{v} \beta 3$ were decreased significantly in the LY294002 group of the DU-145 and PC-3 cells; however, levels of these five proteins were not obviously changed in the LNCAP cells. Each histogram was compared with the semi-quantitative result of western blot analysis; each experiment was repeated at least 3 times, ${ }^{*} \mathrm{P}<0.05,{ }^{* *} \mathrm{P}<0.01,{ }^{* * *} \mathrm{P}<0.001$. PCa, prostate cancer; BSP, bone sialoprotein; OPN, osteopontin; MMP, metalloproteinase; $\alpha \mathrm{v} \beta 3$, integrin alpha $\mathrm{v}$ and integrin beta 3; SB, SB22502 (a specific CXCR2 receptor antagonist); Ctrl, control; LY, LY294002 (Akt inhibitor); U0, U0126 (ERK1/2 inhibitor); S, SB203580 (p38 MAPK inhibitor); SP, SP600125 (JNK1/2 inhibitor).

invading through the Matrigel barrier was less than that of the control groups (Fig. 1B). After the cells were counted under random high magnification, the DU-145 penetration rate of the control group was $71.21 \%$ and that of the SB225002 group was
$26.54 \%(\mathrm{P}=0.005)$. The LNCAP penetration rate of the control group was $84.67 \%$ for the control and $40.31 \%$ after SB225002 treatment $(\mathrm{P}=0.005)$. Finally, the $\mathrm{PC}-3$ penetration rate was $63.44 \%$ for the control and $22.65 \%$ after SB225002 treatment 

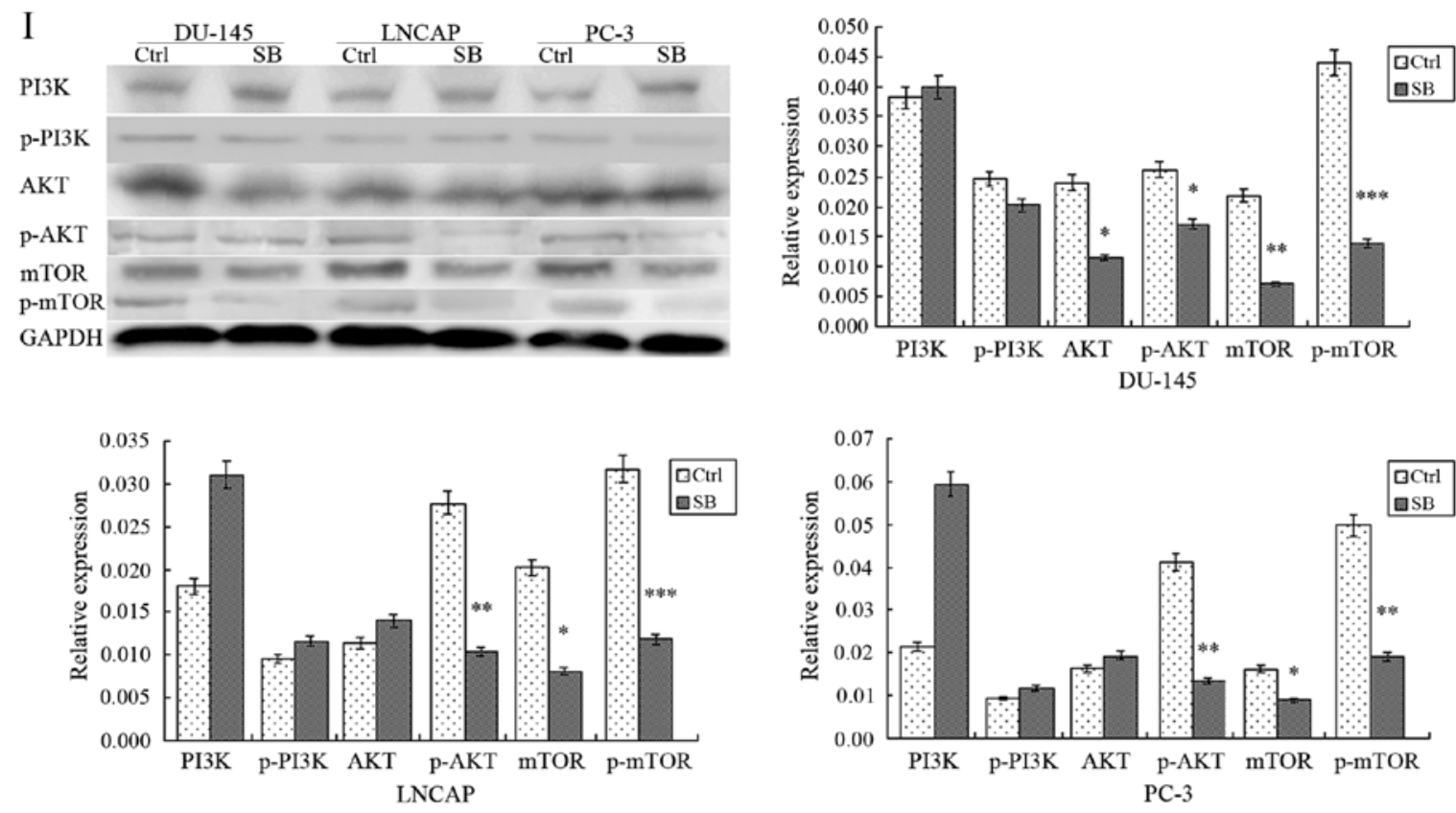

Figure 2. Continued. (I) Expression of p-AKT and p-mTOR was decreased obviously in the DU-145 and PC-3 cells after SB225002 treatment. Each histogram was compared with the semi-quantitative result of western blot analysis; each experiment was repeated at least 3 times, ${ }^{*} \mathrm{P}<0.05,{ }^{* *} \mathrm{P}<0.01,{ }^{* * *} \mathrm{P}<0.001$. $\mathrm{PCa}$, prostate cancer; BSP, bone sialoprotein; OPN, osteopontin; MMP, metalloproteinase; $\alpha v \beta 3$, integrin alpha $\mathrm{v}$ and integrin beta 3; SB, SB22502 (a specific CXCR2 receptor antagonist); Ctrl, control; LY, LY294002 (Akt inhibitor); U0, U0126 (ERK1/2 inhibitor); S, SB203580 (p38 MAPK inhibitor); SP, SP600125 (JNK1/2 inhibitor).

$(\mathrm{P}=0.001)$. For the migration assay (Fig. 1A), after $48 \mathrm{~h}$ of incubation, the wounds in the control groups of the DU-145 and PC3 cells were significantly reduced by $25 \%$ for DU-145 and 30\% for PC-3; however, in the SB225002 group, the two cell lines migrated poorly, showing a decrease of 10 and 5\%, respectively, in wound healing.

Co-expression of BSP/OPN and $\alpha v \beta 3$ in $D U-145$ and $P C-3$ cells. It was reported that BSP/OPN combine with integrin proteins, especially $\alpha v \beta 3$, on the cell surface to promote cell migration and invasion. We used immunofluorescence to determine whether BSP/OPN and $\alpha \mathrm{v} \beta 3$ were co-expressed in the PCa cells (Fig. 2A and B). After labeling with different colors of the fluorescent secondary antibody, BSP and OPN were shown in the images as red fluorescence and $\alpha v \beta 3$ showed green fluorescence. Additionally, nuclei stained with DAPI exhibited blue fluorescence. Co-expression of BSP- $\alpha v \beta 3$ and OPN- $\alpha v \beta 3$ was evident in the DU-145 and PC-3 cells.

$S B 225002$ inhibits the expression of $B S P, O P N, M M P 2, M M P 9$ and $\alpha v \beta 3$ in PCa cells. To explore the molecular mechanism of the suppression of PCa invasion by SB225002, western blotting was performed after treatment of the three $\mathrm{PCa}$ cell lines with SB225002 $\left(5 \times 10^{-6} \mathrm{M}\right.$ in $\left.72 \mathrm{~h}\right)$. The results showed that the expression levels of BSP, MMP-2 and OPN were reduced significantly following SB225002 treatment compared with levels noted in the control group: BSP was reduced by 9.04-fold in DU-145 cells, by 1.7-fold in LNCAP cells and by 5.4-fold in PC-3 cells; OPN was reduced by 3.0-fold in DU-145 and PC-3 cells and by 2.8 -fold in LNCAP cells; MMP-2 was reduced by 3.2 -fold in DU-145 cells, by 5.2 -fold in PC-3 cells and by 4.5 -fold in LNCAP cells, $\mathrm{P}<0.05$ (Fig. 2C). Regarding MMP-9 and $\alpha v \beta 3$, the expression levels of both proteins were not reduced significantly in the LNCAP cells $(\mathrm{P}=0.08)$, while MMP-9 expression was decreased by 3.7-fold in the DU145 cells, and $\alpha v \beta 3$ expression was reduced by 1.3 -fold in the PC- 3 cells. These results indicate that SB225002 may suppress PCa invasion through restraining the expression of BSP, MMP-2 and OPN.

ERK, JNK, P38 and PI-3K signaling pathways mediate the expression of BSP, OPN, MMP-2, MMP-9 and $\alpha v \beta 3$. To identify which signal transduction pathway(s) regulate several of the abovementioned invasion-related protein expression levels, we applied the inhibitors LY294002 (Akt inhibitor), U0126 (ERK1/2 inhibitor), SB203580 (p38 MAPK inhibitor), and SP600125 (JNK1/2 inhibitor) and detected the expression of these proteins by western blotting. The three cancer cell lines were treated with LY294002 $\left(10^{-6} \mathrm{M}\right)$, U0126 $\left(10^{-6} \mathrm{M}\right)$, SB203580 $\left(10^{-6} \mathrm{M}\right)$, and SP600125 $\left(10^{-6} \mathrm{M}\right)$ for $72 \mathrm{~h}$. The findings revealed that BSP, OPN, MMP- 2 and $\alpha v \beta 3$ protein levels were significantly lower in the DU-145 and PC-3 cells after LY294004 treatment than after the other inhibitor treatments (Fig. 2D-F and H). This result is consistent with previous reports that PI3K can regulate tumor cell invasion. Although the expression level of MM-9 in the LY29402 treatment group was lower than that in the control group (DU-145 and PC-3), the difference was not statistically significant (Fig. 2G). Regarding LNCAP cells, although the BSP and MMP-9 expression levels were reduced, no statistically significant difference was noted, and no obvious expression changes were found in the remaining three proteins (OPN, MMP-2 and $\alpha v \beta 3$ ) after LY294002 treatment in LNCAP cells. Moreover, in the SP600125 treatment group, we found that the expression levels of BSP and $\alpha v \beta 3$ showed little reduction, especially in DU-145 and PC-3 cells, suggesting that the JNK signaling pathway can also regulate tumor cell invasion. 
A

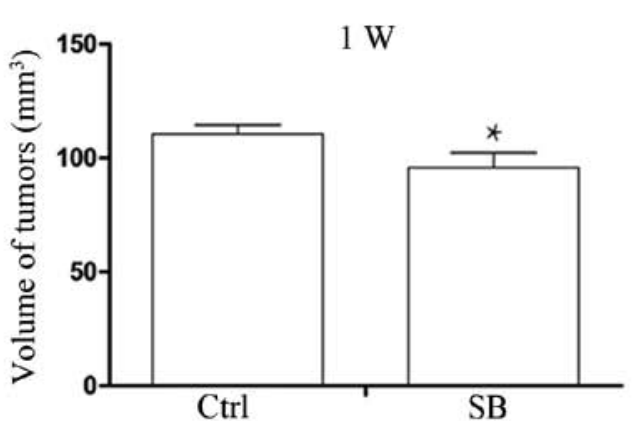

C

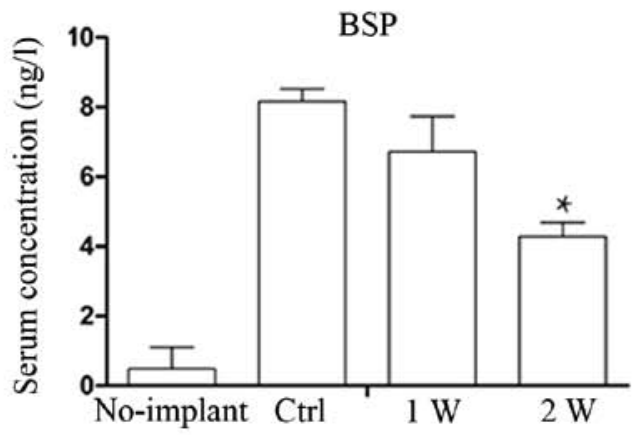

B

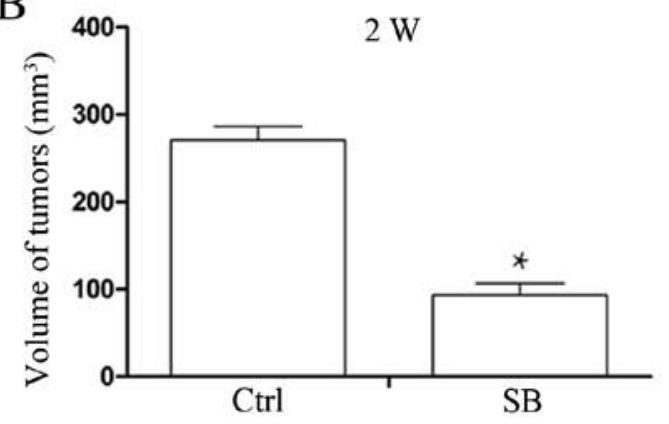

D

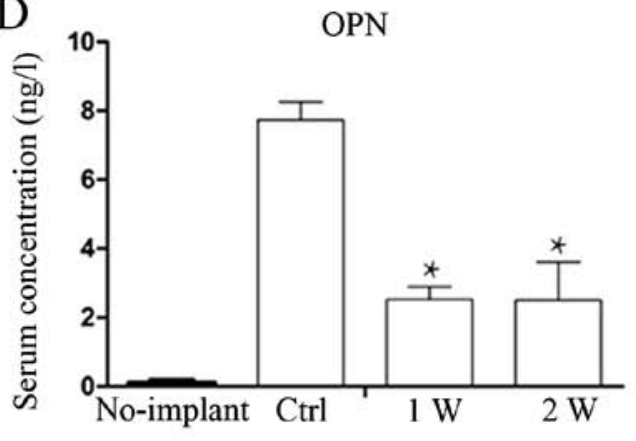

E

Ctrl

$1 \mathrm{~W}$

$2 \mathrm{~W}$

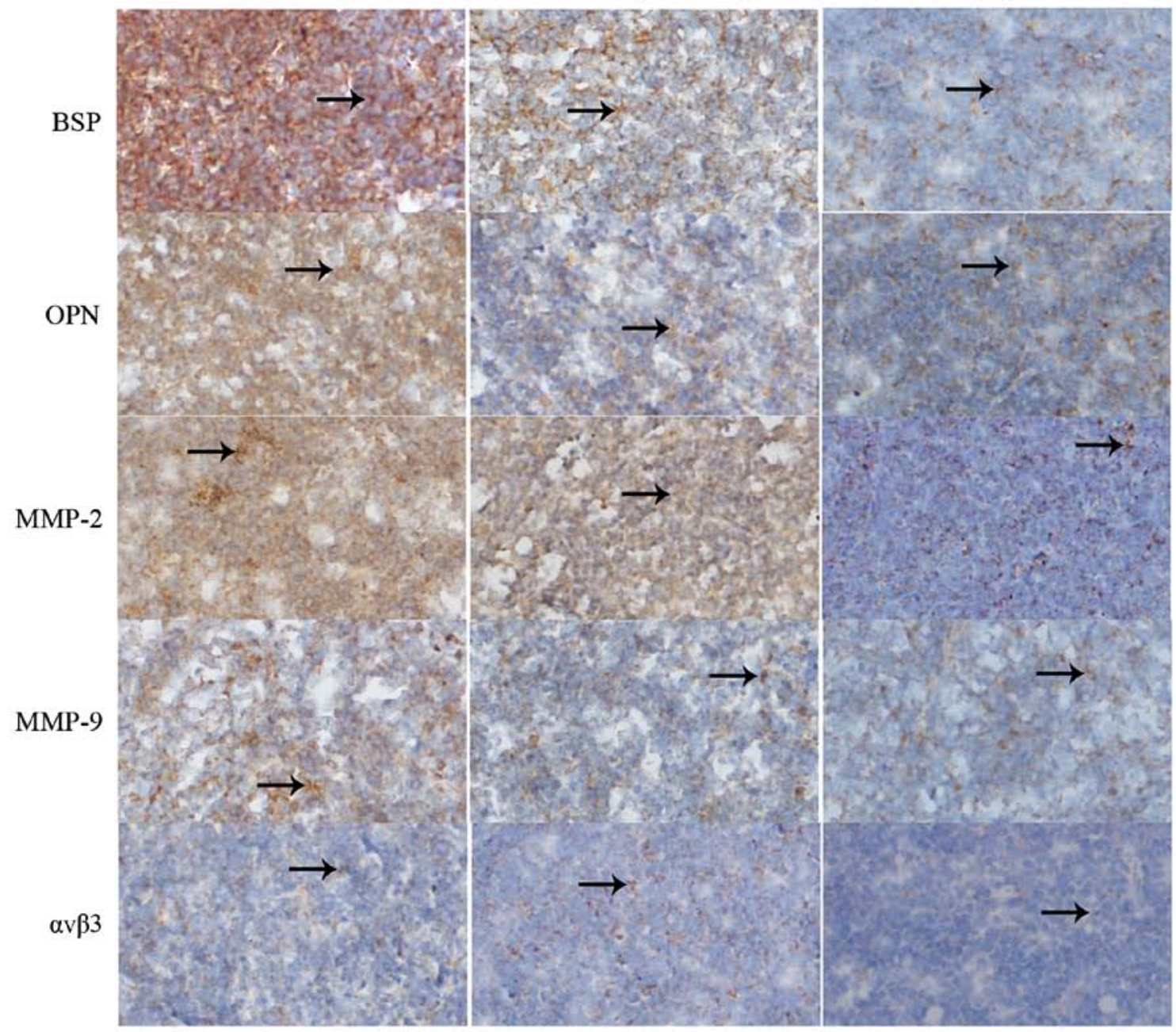

Figure 3. Subcutaneous tumorigenesis in mice was used to examine the effect of SB225002 on DU-145 cells in vivo. (A and B) At the end of the intraperitoneal injection at 1 week (W) and $2 \mathrm{~W}$, the tumor volumes were measured, and SB225002 (SB) was found to inhibit xenograft tumor growth obviously after 2 weeks. (C and D) The serum levels of BSP and OPN were detected by ELISA, and the results showed that BSP and OPN secreted by xenograft tumors were significantly decreased after $2 \mathrm{~W}$ of SB225002 injection ("P<0.05). (E) The expression levels of the five invasion-related proteins in the xenograft tumor tissues were detected by immunohistochemistry at $1 \mathrm{~W}$ and $2 \mathrm{~W}$. Arrows indicate protein-positive expression. Ctrl, control; BSP, bone sialoprotein; OPN, osteopontin. 
Table II. Expression intensity assessments of five proteins.

\begin{tabular}{lccccc}
\hline & BSP & OPN & MMP-2 & MMP-9 & $\alpha v \beta 3$ \\
\hline Ctrl & +++ & +++ & +++ & ++ & + \\
1 week & ++ & + & ++ & + & + \\
2 weeks & + & + & + & + & - \\
\hline
\end{tabular}

BSP, bone sialoprotein; OPN, osteopontin; MMP-2, metalloproteinase 2; $\alpha \mathrm{v} \beta 3$, integrin alpha $\mathrm{V}$ and integrin beta 3; Ctrl, control.

SB225002 inhibits the phosphorylation/activation of AKT and mTOR. To identify the effect of SB225002 on the PI3K signaling pathway, we treated the three PCa cell lines with SB225002 $\left(10^{-6} \mathrm{M}\right.$ for $\left.72 \mathrm{~h}\right)$. The primary proteins of the PI3K signaling pathway (PI3K/p-PI3K, AKT/p-AKT and $\mathrm{mTOR} / \mathrm{p}-\mathrm{mTOR}$ ) were detected by western blotting. The result shows that SB225002 did not significantly promote the phosphorylation of PI3K, and PI3K expression was not significantly changed. When we further detected the PI3K downstream protein AKT, only DU-145 cells demonstrated a decrease in the expression of AKT, and AKT in LNCAP and PC-3 cells was not changed; however, phosphorylated Akt in all three cancer cell lines showed a significant downward trend. Finally, the expression levels of mTOR and p-mTOR in the SB225002 group were lower than those of the control group (Fig. 2I). The above results illustrate that SB225002 has a certain blocking effect on the PI3K signaling pathway, and this block effect may begin with the inhibition of phosphorylation of AKT.

SB225002 suppresses PCa cell growth and the secretion of $B S P$ and $O P N$ in. Toexamine whether SB225002 inhibits the secretion of BSP and OPN from PCa cells in vivo, after the xenografts were harvested at 1 week $(\mathrm{W})$ and $2 \mathrm{~W}$, whole blood from the treated and control group mice was obtained from the eye artery, and enzyme-linked immunosorbent assay was performed after centrifuging the blood at $1,000 \mathrm{rpm}$ for $10 \mathrm{~min}$. The results revealed that the serum BSP and OPN levels in the no implant mice were low BSP, $0.724 \pm 0.3 \mathrm{ng} / \mathrm{l}$; OPN, $0.132 \pm 0.01 \mathrm{ng} / \mathrm{l})$. However, after two weeks of SB225002 administration, the serum levels of BSP $(9.201 \pm 0.4 \mathrm{ng} / 1$ in the control group and $4.821 \pm 0.6 \mathrm{ng} / 1 \mathrm{in}$ the SB225002 group; $\mathrm{P}=0.01)$ and $\mathrm{OPN}(8.431 \pm 0.5 \mathrm{ng} / \mathrm{l}$ in the control group and $3.812 \pm 1.4 \mathrm{ng} / 1$ in the SB225002 group; $\mathrm{P}=0.04)$ were decreased by 2 -fold compared with the levels in the control group (Fig. 3C and D), indicating that SB225002 can inhibit PCa cell secretion of BSP and OPN in vivo. We also measured the volume of the xenografts at $1 \mathrm{~W}$ and $2 \mathrm{~W}$ after SB225002 injection. At the end of the first week, the tumor volume was $110.5709 \pm 3.98 \mathrm{~mm}^{3}$ in the control group and $95.8498 \pm 6.49 \mathrm{~mm}^{3}$ in the SB225002 group. At the end of the second week, the tumor volume of the control group had reached $270.7950 \pm 15.59 \mathrm{~mm}^{3}$, and the tumor volume of the SB225002 group was $93.3554 \pm 13.34 \mathrm{~mm}^{3}(\mathrm{P}=0.006)$ (Fig. 3A and B). The BSP, OPN and MMP-2 expression levels in xenografts were similarly determined by immunohistochemistry. In xenografts, positively expressed proteins were stained to yellow or brown yellow and appears in the shape of dot or sheet. The arrows indicate protein positive expression (Fig. 3E). The expression levels of BSP, OPN and MMP-9 were significantly decreased after SB225002 injection for one week, while MMP-2 expression level remained strongly. But the MMP-2 expression was significantly reduced after two weeks of injection. As for $\alpha \mathrm{V} \beta 3$, there was no significant change before and after SB225002 injection. After 2 weeks, the positive staining scores of the five proteins were calculated and are shown in Table II.

\section{Discussion}

Invasion and metastasis are two major obstacles to the treatment of malignant tumors $(1,2)$. Many patients lose the chance of surgical treatment due to the transfer of primary tumors to distant organs. For PCa, although most patients respond initially to androgen removal, most patients eventually develop castration resistance and have a high risk of bone metastases (21). Thus, there is an urgent need to explore effective strategies to prevent distant tumor metastasis to improve the prognosis of patients.

At the molecular level, malignant cells must be able to detach from their primary tissues, evade the host immune system, cross the walls of the vasculature, penetrate through the extracellular matrix in tissue, and finally take up residence and survive in tissues quite different from their origins (3). Studies over recent years have suggested that, besides MMP family proteins, small integrin binding ligand $\mathrm{N}$-linked glycoproteins (SIBLINGs) also regulate many of the activities required for the distant metastasis of tumor cells, especially for malignant bone metastases. Additionally, the serum levels of BSP and OPN (two primary proteins of the SIBLING family and the most frequently investigated) are often used to predict the occurrence of bone metastases (2,7,9-11). As mentioned previously, BSP and OPN contain an integrin-binding RGD (Arg-Gly-Asp) sequence that can bind to integrins to enhance the invasion and adhesion of tumor cells (29). However, OPN peptides must be cleaved by MMP-9 first, followed by the enhancement of matrix degradation by activating MMP-3 (38). In terms of immune escape, after tumor cells enter the vasculature, these two SIBLINGs can bind complement factor $\mathrm{H}$ and prevent tumor cells from complement attack (30). In addition, some studies have indicated that SIBLING proteins can also be combined with the CD44 regulation of tumor cell proliferation and apoptosis (3). Because SIBLINGs are important factors in the regulation of tumor metastasis, to decrease tumor cell expression, SIBLINGs may be an efficiency strategy by which to overcome the distant metastasis of PCa. Many studies have reported that phosphoinositide-3-kinase (PI3K) is an important signaling pathway responsible for malignant neoplasm growth and transformation processes (31). For invasion, the PI3K signaling pathway mediates the expression of MMP-2 and MMP-9 (32,33). Zhang et al demonstrated that the PI3K/Akt pathway inhibitor LY294002 attenuated the migration, invasion, expression and activity of MMP and expression of p-PI3K and p-Akt in U87 and U251 cells (34). However, few studies have reported on the factors that regulate SIBLING expression. In this study, a series of in vitro and in vivo experiments confirmed that SB225002 could decrease PCa expression of BSP and OPN through the PI3K pathway. 
As our results showed, following treatment of three prostate cell lines with different concentrations of SB225002, concentration- and time-dependent growth inhibition was demonstrated in DU145 and PC-3 cells but not in LNCAP cells. The lack of an effect in LNCAP cells is likely due to LNCAP belonging to the androgen-dependent cell group, and some reports have demonstrated that IL- 8 and its receptors are not expressed or negligibly expressed in androgen-dependent PCa (18,35-37). Additionally, the Transwell assay exhibited that SB225002 could decrease the number of cancer cells that crossed the Matrigel barrier, indicating that SB225002 can reduce the invasion of $\mathrm{PCa}$ cells. Many studies have demonstrated SIBLING and integrin expression in breast cancer, but few have been reported in PCa. Considering that SIBLINGs enhance invasion through combining with integrin receptors, we evaluated the co-expression of BSP, OPN and $\alpha v \beta 3$ in DU-145 and PC-3 cells, and immunofluorescence analysis indicated all three proteins were expressed in PCa. Simultaneously, western blotting was performed to detect the influence of SB225002 on these invasion-related proteins, and SB225002 treatment was found to decrease the expression of BSP, OPN and MMP-2 in the three cell lines. However, MMP-9 expression was only reduced in DU-145 cells, and SB2250022 did not inhibit the expression of $\alpha v \beta 3$. By contrast, following treatment with SB225002 treatment, the $\alpha v \beta 3$ expression levels showed an increasing trend in the three cell lines. Next, we treated cells with different signaling pathway inhibitors to detect which pathways control tumor cell invasion primarily. After U0126, SP600125, SB230580 and LY294002 treatment, the expression of the five proteins in the LY294002 group was obviously inhibited, consistent with previous reports describing that $\mathrm{PI} 3 \mathrm{~K}$ regulates the invasion of malignant neoplasms (32-34). Next, we tested the signaling protein in the PI3K pathway in the SB225002 and control groups to determine whether SB225002 suppresses PCa cell invasion through the PI3K pathway. Western blotting showed that, in the SB225002 group, P-AKT expression was decreased obviously, the expression levels of downstream protein mTOR and P-mTOR were significantly reduced, and the expression levels of PI3K and P-PI3K did not change, suggesting that the function of SB225002 to restrain tumor cell invasion was achieved by inhibiting the phosphorylation of AKT. Finally, we implanted DU-145 cells into mice subcutaneously, through two weeks of continuous intraperitoneal administration and confirmed that SB225002 suppressed PCa cell expression and secretion of BSP and OPN in vivo, in addition to MMP-2.

In conclusion, many studies have confirmed that SB225002 is an IL-8 receptor antagonist $(17,38,39)$. SB225002 exhibits many antitumor effects by blocking the binding of IL-8 to CXCR2 receptors. This experiment confirmed that SB225002 has an inhibitory effect on the expression of invasion-related proteins. These findings may provide new ideas and methods to prevent the distant metastasis of tumors in clinical practice.

\section{Acknowledgements}

We would like to thank Professor Huamao Jiang for technical guidance in this experiment.

\section{Funding}

The present study was supported by the National Natural Science Foundation of China (no. 81672265) and the Distinguished Professor Fund of Liaoning Provincial Department of Education [Liaojiaofa (2015) no. 153].

\section{Availability of data and materials}

The datasets analyzed during the current study are available from the corresponding author on reasonable request.

\section{Author's contributions}

HJ and MX conceived and designed the study. MX, JL, HW, BL and ZG performed the experiments. MX wrote the paper. $\mathrm{HJ}$ and HW reviewed and edited the manuscript. All authors read and approved the manuscript and agree to be accountable for all aspects of the research in ensuring that the accuracy or integrity of any part of the work are appropriately investigated and resolved.

\section{Ethics approval and consent to participate}

The animal experiment was approval by the JinZhou University Laboratory Animal Ethics Review Committee (JinZhou, China).

\section{Patient consent for publication}

Not applicable.

\section{Competing interests}

The authors state that they have no competing interests.

\section{References}

1. Weigelt B, Peterse JL and van't Veer LJ: Breast cancer metastasis: Markers and models. Nat Rev Cancer 5: 591-602, 2005.

2. Rizzoli R, Body JJ, Brandi ML, Cannate-Andia J, Chappard D, El Maghraoui A, Glüer CC, Kendler D, Napoli N, Papaioannou A, et al: Cancer-associated bone disease. Osteoporos Int 24: 2929-2953, 2013.

3. Kruger TE, Miller AH, Godwin AK and Wang J: Bone sialoprotein and osteopontin in bone metastasis of osteotropic cancers. Crit Rev Oncol Hematol 89: 330-341, 2014.

4. Chen J, Rodriguez JA, Barnett B, Hashimoto N, Tang J and Yoneda T: Bone sialoprotein promotes tumor cell migration in both in vitro and in vivo models. Connect Tissue Res 44 (Suppl 1): S279-S284, 2003.

5. Gordon JA, Sodek J, Hunter GK and Goldberg HA: Bone sialoprotein stimulates focal adhesion-related signaling pathways: Role in migration and survival of breast and prostate cancer cells. J Cell Biochem 107: 1118-1128, 2009.

6. Anunobi CC, Koli K, Saxena G, Banjo AA and Ogbureke KU: Expression of the SIBLINGs and their MMP partners in human benign and malignant prostate neoplasms. Oncotarget 7: 48038-48049, 2016.

7. Righi L, Bollito E, Ceppi P, Mirabelli D, Tavaglione V, Chiusa L, Porpiglia F, Brunelli M, Martignoni G, Terrone C and Papotti M: Prognostic role of bone sialoprotein in clear cell renal carcinoma. Anticancer Res 33: 2679-2687, 2013.

8. Zhang L, Hou X, Lu S, Rao H, Hou J, Luo R, Huang H, Zhao H, Jian H, Chen Z, et al: Predictive significance of bone sialoprotein and osteopontin for bone metastases in resected Chinese non-small-cell lung cancer patients: A large cohort retrospective study. Lung Cancer 67: 114-119, 2010. 
9. D'Oronzo S, Brown J and Coleman R: The value of biomarkers in bone metastasis. Eur J Cancer Care (Engl) 26, 2017.

10. Wang Y, Zhang XF, Dai J, Zheng YC, Zhang MG and He JJ: Predictive value of serum bone sialoprotein and prostate-specific antigen doubling time in patients with bone metastasis of prostate cancer. J Huazhong Univ Sci Technolog Med Sci 33: 559-562, 2013.

11. Wei RJ, Li TY, Yang XC, Jia N, Yang XL and Song HB: Serum levels of PSA, ALP, ICTP, and BSP in prostate cancer patients and the significance of ROC curve in the diagnosis of prostate cancer bone metastases. Genet Mol Res 15: gmr7707, 2016.

12. Bellahcène A, Castronovo V, Ogbureke KU, Fisher LW and Fedarko NS: Small integrin-binding ligand N-linked glycoproteins (SIBLINGs): Multifunctional proteins in cancer. Nat Rev Cancer 8: 212-226, 2008.

13. Wang J, Wang L, Xia B, Yang C, Lai H and Chen X: BSP gene silencing inhibits migration, invasion, and bone metastasis of MDA-MB-231BO human breast cancer cells. PLoS One 8 e62936, 2013.

14. Waltregny D, Bellahcène A, de Leval X, Florkin B, Weidle U and Castronovo V: Increased expression of bone sialoprotein in bone metastases compared with visceral metastases in human breast and prostate cancers. J Bone Miner Res 15: 834-843, 2000 .

15. Khodavirdi AC, Song Z, Yang S, Zhong C, Wang S, Wu H, Pritchard C, Nelson PS and Roy-Burman P: Increased expression of osteopontin contributes to the progression of prostate cancer. Cancer Res 66: 883-888, 2006.

16. Lecrone V,Li W, Devoll RE, Logothetis C andFarach-Carson MC: Calcium signals in prostate cancer cells: Specific activation by bone-matrix proteins. Cell Calcium 27: 35-42, 2000.

17. Sueoka H, Hirano T, Uda Y, Iimuro Y, Yamanaka $J$ and Fujimoto J: Blockage of CXCR2 suppresses tumor growth of intrahepatic cholangiocellular carcinoma. Surgery 155: 640-649, 2014.

18. Huang J, Yao JL, Zhang L, Bourne PA, Quinn AM, di Sant'Agnese PA and Reeder JE: Differential expression of interleukin-8 and its receptors in the neuroendocrine and non-neuroendocrine compartments of prostate cancer. Am J Pathol 166: 1807-1815, 2005

19. Li X, Wang S, Zhu R, Li H, Han Q and Zhao RC: Lung tumor exosomes induce a pro-inflammatory phenotype in mesenchymal stem cells via NFKB-TLR signaling pathway. J Hematol Oncol 9: 42, 2016.

20. Arenberg DA, Kunkel SL, Polverini PJ, Glass M, Burdick MD and Strieter RM: Inhibition of interleukin-8 reduces tumorigenesis of human non-small cell lung cancer in SCID mice. J Clin Invest 97: 2792-2802, 1996.

21. Chen K, Wu K, Jiao L, Wang L, Ju X, Wang M, Di Sante G, Xu S, Wang Q, Li K, et al: The endogenous cell-fate factor dachshund restrains prostate epithelial cell migration via repression of cytokine secretion via a cxcl signaling module. Cancer Res 75 : 1992-2004, 2015.

22. Neveu B, Moreel X, Deschênes-Rompré MP, Bergeron A, LaRue H, Ayari C, Fradet Y and Fradet V: IL-8 secretion in primary cultures of prostate cells is associated with prostate cancer aggressiveness. Res Rep Urol 6: 27-34, 2014.

23. Ha NH, Park DG, Woo BH, Kim DJ, Choi JI, Park BS, Kim YD, Lee JH and Park HR: Porphyromonas gingivalis increases the invasiveness of oral cancer cells by upregulating IL-8 and MMPs. Cytokine 86: 64-72, 2016.

24. De Larco JE, Wuertz BR, Rosner KA, Erickson SA, Gamache DE, Manivel JC and Furcht LT: A potential role for interleukin-8 in the metastatic phenotype of breast carcinoma cells. Am J Pathol 158: 639-646, 2001.

25. MacManus CF, Pettigrew J, Seaton A, Wilson C, Maxwell PJ, Berlingeri S, Purcell C, McGurk M, Johnston PG and Waugh DJ: Interleukin-8 signaling promotes translational regulation of cyclin D in androgen-independent prostate cancer cells. Mol Cancer Res 5: 737-748, 2007.
26. Araki S, Omori Y, Lyn D, Singh RK, Meinbach MD, Sandman Y, Lokeshwar VB and Lokeshwar BL: Interleukin-8 is a molecular determinant of androgen independence and progression in prostate cancer. Cancer Res 67: 6854-6862, 2007.

27. Du M, Qiu Q, Gruslin A, Gordon G, He M, Chan CC, Li D and Tsang BK SB225002 promotes mitotic catastrophe in chemo-sensitive and -resistant ovarian cancer cells independent of p53 status in vitro. PLoS One 8: e54572, 2013.

28. de Vasconcellos JF, Laranjeira AB, Leal PC, Bhasin MK, Zenatti PP, Nunes RJ, Yunes RA, Nowill AE, Libermann TA, Zerbini LF and Yunes JA: SB225002 induces cell death and cell cycle arrest in acute lymphoblastic leukemia cells through the activation of GLIPR1. PLoS One 10: e0134783, 2015.

29. Rapuano BE and MacDonald DE: Structure-activity relationship of human bone sialoprotein peptides. Eur J Oral Sci 121: 600-609, 2013

30. Fedarko NS, Fohr B, Robey PG, Young MF and Fisher LW: Factor $\mathrm{H}$ binding to bone sialoprotein and osteopontin enables tumor cell evasion of complement-mediated attack. J Biol Chem 275 16666-16672, 2000.

31. Okkenhaug K and Vanhaesebroeck B: PI3K in lymphocyte development, differentiation and activation. Nat Rev Immunol 3: 317-330, 2003.

32. Ku MJ, Kim JH, Lee J, Cho JY, Chun T and Lee SY: Maclurin suppresses migration and invasion of human non-small-cell lung cancer cells via anti-oxidative activity and inhibition of the Src/FAK-ERK- $\beta$-catenin pathway. Mol Cell Biochem 402: 243-252, 2015

33. Tseng CH, Tzeng CC, Chiu CC, Hsu CY, Chou CK and Chen YL: Discovery of 2-[2-(5-nitrofuran-2-yl)vinyl)quinoline derivatives as a novel type of antimetastatic agents. Bioorg Med Chem 23: 141-148, 2015.

34. Zhang FY, Hu Y, Que ZY, Wang P, Liu YH, Wang ZH and Xue YX: Shikonin inhibits the migration and invasion of human glioblastoma cells by targeting phosphorylated $\beta$-catenin and phosphorylated PI3K/Akt: A potential mechanism for the anti-glioma efficacy of a traditional Chinese herbal medicine. Int J Mol Sci 16: 23823-23848, 2015.

35. Murphy C, Mcgurk M, Prttigrew J, Santinelli A, Mazzucchelli R, Johnston PG, Montironi R and Waugh DJ: Nonapical and cytoplasmic expression of interleukin-8, CXCR1, and CXCR2 correlates with cell proliferation and microvessel density in prostate cancer. Clin Cancer Res 11: 4117-4127, 2005

36. Seaton A, Scullin P, Mxawell PJ, Wilson C, Prttigrew J, Gallagher R, O'Sullivan JM, Johnston PG and Waugh DJ: Interleukin-8 signaling promotes androgen-independent proliferation of prostate cancer cells via induction of androgen receptor expression and activation. Carcinogenesis 29: 1148-1156, 2008.

37. Tanaka H, Kono E, Tran CP, Miyazaki H, Yamashiro J, Shimomura T, Fazli L, Wada R, Huang J, Vessella RL, et al: Monoclonal antibody targeting of N-cadherin inhibits prostate cancer growth, metastasis and castration resistance. Nat Med 16 1414-1420, 2010.

38. Takafuji V, Forgues ME, Unsworth E, Goldsmith P and Wang X: An osteopontin fragment is essential for tumor cell invasion in hepatocellular carcinoma. Oncogene 26: 6361-6371, 2007.

39. Manjavachi MN, Quintão NL, Campos MM, Deschamps IK, Yunes RA, Nunes RJ, Leal PC and Calixto JB: The effects of the selective and non-peptide CXCR2 receptor antagonist SB225002 on acute and long-lasting models of nociception in mice. Eur J Pain 14: 23-31, 2010

This work is licensed under a Creative Commons Attribution-NonCommercial-NoDerivatives 4.0 International (CC BY-NC-ND 4.0) License. 